\title{
Design and Realization of Distribution Static Synchronous Compensator
}

\author{
Zeng Linsuo \\ Dept.of Electrical Engineering and Automation \\ Shenyang University of Technology \\ Shenyang,China \\ e-mail: zls1014@hotmail.com
}

\author{
Chen Feng \\ Dept.of Electrical Engineering and Automation \\ Shenyang University of Technology \\ Shenyang,China \\ e-mail: 297307385@163.com
}

\begin{abstract}
According to the engineering requirement of power distribution network reactive power compensation, the paper presents a software and hardware design method of the STATCOM based on DSP. In order to stabilize the PCC voltage around a prescribed value in the direct current control mode, the three-level converter of three phase bridge of the equipment in main circuit was connected to power net with coupling transformer. The paper mainly introduced the development of STATCOM device controller based on DSP(TMS320F2812) and presents the detailed design methods of DSP controller such as signal conditioning circuit, synchronous detection circuit, driving circuit of IPM. At the same time, the paper presents the software function module of STATCOM system. The STATCOM based on such method has been applied in an experimental flat roof.The detecting results of STATCOM for voltage compensation show that the design STATCOM meet the voltage compensation requirements, and the reactive power compensation effect is obvious, and proved the correctness and feasibility of the device.
\end{abstract}

Keywords-STATCOM; DSP; hardware design; voltage compensation; reactive power

\section{INTRODUCTION}

With the rapid growth of high-power electronic devices and Flexible AC Transmission System(FACTS) technology was referred to, FACTS devices in power system development and its application by the increasingly widespread attention.The static synchronous compensator(STATCOM) which as an important member of FACTS family, also known as Advanced Static Var Generator(ASVG), can be from the entire range of inductive to capacitive reactive power in the continuous adjustment,particularly in underdeveloped pressure can still be validly issued under the conditions of reactive power, the power industry has been more and more attention.

In the power system, reactive power does not directly as the actual consumption, only for the circuit between the electric and magnetic fields of alternating, which provide energy for electrical and mechanical energy conversion.However, the power loss and reactive power alternating from the generation and transmission equipments would lead to voltage drop and power loss. The traditional quality of voltage control device (such as static non power compensator SVC) because of its slow speed of response, it is difficult to meet the requirements for quality control of dynamic voltage. Static synchronous
compensator(STATCOM) is an important "custom power" device based on power electronic components which can comprehensive treatment of various electric power grid in the power quality problems[1-3]. Compared with the traditional power compensator, STATCOM has a fast dynamic response that it can adjust continuously,beside this, it has the advantages of low loss and small volume.

This paper designed a distribution static synchronous compensator based on TMS320F2812, offered the main circuit and working processnon of reactive power compensator.The experimental results of STATCOM for voltage compensation showed that the design STATCOM meet the voltage compensation requirements and can better compensate reactive power.At the same time, the STACOM designed in this paper can provide a reference for the design of other types of power electronic device.

\section{THE BASIC OPERATIONAL PRINCIPLE AND THE STRUCTURE SYSTEM OF STATCOM}

\section{A. The basic principle of STATCOM operation}

The principle of STATCOM operation shown in Fig.1. The DC side capacitor provide the DC voltage support. The inverter reverse $\mathrm{DC}$ voltage into $\mathrm{AC}$ voltage.To adjust the size, frequency and phase of the AC voltage by controlling the driving pulse of switch components. The STATCOM device is connected in parallel to power system througn a link transformer.The leakage reactance of link transformer itself which can limit the current to prevent causing a large current at the inverter or system failure.The whole STATCOM system is equivalent to a voltage controlled voltage source.

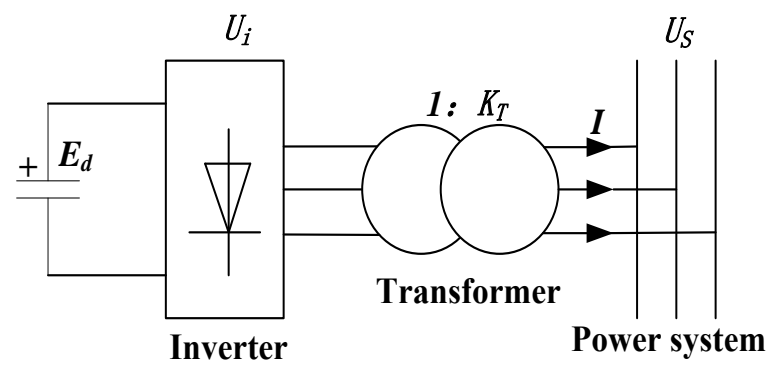

Figure 1. Principle of STATCOM operation diagram

The voltage Ui is generated by STATCOM and the Us is system voltage. When $\mathrm{Ui}=\mathrm{Us}$, the inverter has no output.When $\mathrm{Ui}<\mathrm{Us}$, the inverter is equivalent to an 
inductance which absorb reactive power from the grid. When $\mathrm{Ui}>\mathrm{Us}$, the inverter is equivalent to a capacitance which output reactive power to power grid.Due to continuous and rapid controlling the size of the $\mathrm{Ui}$, reactive power absorption of STATCOM can be regulated continuously and rapidly from the positive to the negative.

\section{B. The structure system of STATCOM}

The overall design idea of STATCOM as shown in Fig .2. This design includes sampling device, filtering device, control device and driving device. Closed-loop control mode was used in this design. The required input parameters is three-phase voltage and output parameters are three-phase current of the inverter output[4]. The power switching devices can use IGBT which have the higher switching frequency, and adopts SPWM modulation technology which is conducive to reduce the output harmonic content of DSTATCOM device[5]. The output voltage of the inverter is applied to the power grid through LC filter(Can also be connected to the grid through a transformer).The control system is mainly composed by DSP which mainly completes the signal sampling and control algorithm, and generate consistent with the requirements of the pulse signal.

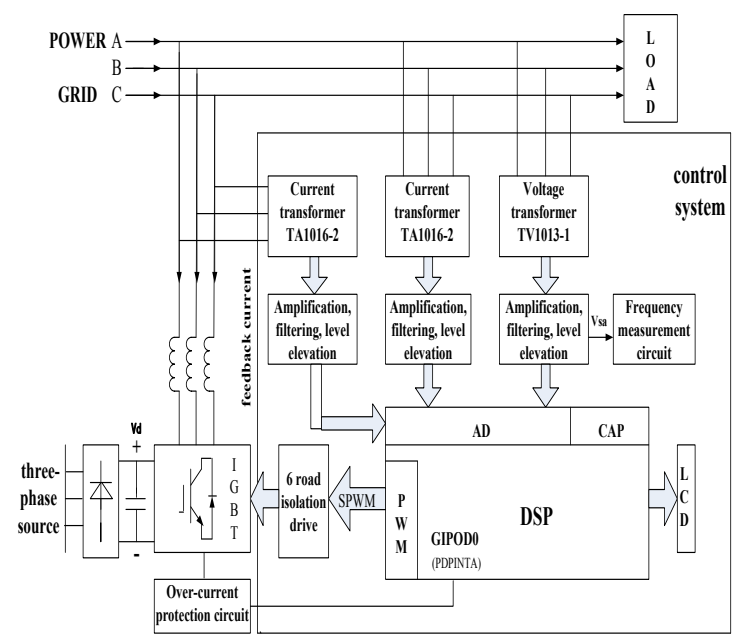

Figure 2. The overall structure of the system

\section{THE HARDWARE DESIGN OF THE CONTROL SYSTEM[6]}

The hardware of the control system is composed of an experimental prototype, current source inverter, DSP controller, signal processing circuit, protection circuit, communication interface circuit, drive circuit and other parts.Fig .3 is a block diagram of hardware DSP digital control.

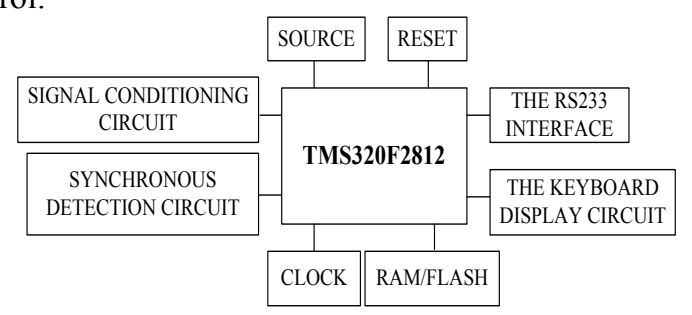

Figure 3. The hardwareblock diagram of the DSP digital control
TMS320F2812 uses this system is a fixed-point DSP chip of TI Corporation TMS320C2000 series.This chip based on $\mathrm{C} / \mathrm{C}++$ high performance 32 bit TMS320C28xDSP kernel which can easily realize the floating-point arithmetic in fixed-point processor because it provide floating point math library[7-8].Now, it had widely used in the high precision servo control, variable frequency power supply, UPS power supply etc. At the same time, it is the best choice for digital control of motor upgrade product.

\section{A. Signal conditioning circuit}

Signal conditioning[9] is what power signal step-down by sensor and then amplified by diode and low pass filter to filter the harmonic by R16, C9 and C10, then, through VR-tube D2 to get a current signal with fixed amplitude,f inally, through the R17 into a voltage signal, so it is suitable for the treatment of DSP.As shown in Fig .4.

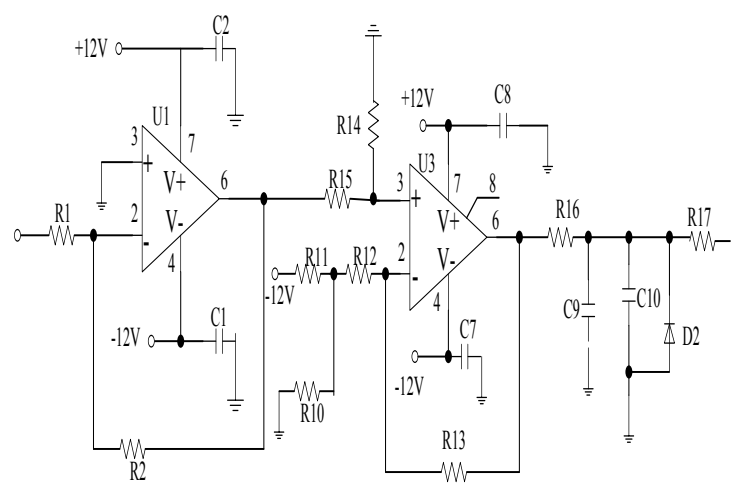

Figure 4. Signalconditioning circuit

\section{B. Synchronous detection circuit}

Controller of voltage and current signals collected in each cycle of each signal sample 1024 times, each cycle 1024 times sampling can completely meet the needs of most of the fundamental and harmonic[10].

The PLL frequency multiplier circuit in this paper, the voltage signal shaping phase after the 1024 octave, as the synchronous sampling interrupt signal by signal frequency doubling, DSP interrupt is edge triggered interrupt sampling by falling edge of sync signal trigger.

Using this sampling method can accurately track the power frequency change to try to accurately sampling.Shaping circuit using the comparator LM339 which can reshap a voltage signal shaping from the transformer to the square wave signal.This square wave signal provides frequency circuit, at the same time it also to the DSP control procedures to provide a periodic signal.Shaping circuitas shown in Fig .5.

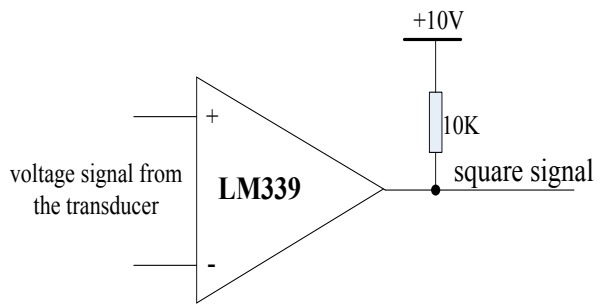

Figure 5. Shaping circuit 
Frequency doubling circuit consists of a phase locked loop CD4046 and frequency division circuit CD4520.As shown in Fig .6.In this circuit,CD4046 output signal dividing frequency to 1024 through CD4520 and then import to the feedback end of CD4046[11]. The internal VCO(voltage controlled oscillator) of CD4046 maintain the input signal and feedback signal synchronization by improving the outputsignal frequency, so as to achievethe purpose ofthefrequency doubling. Here we can use the output signal of doubling circuit as the interrupt signal of $\mathrm{A} / \mathrm{D}$ conversion.

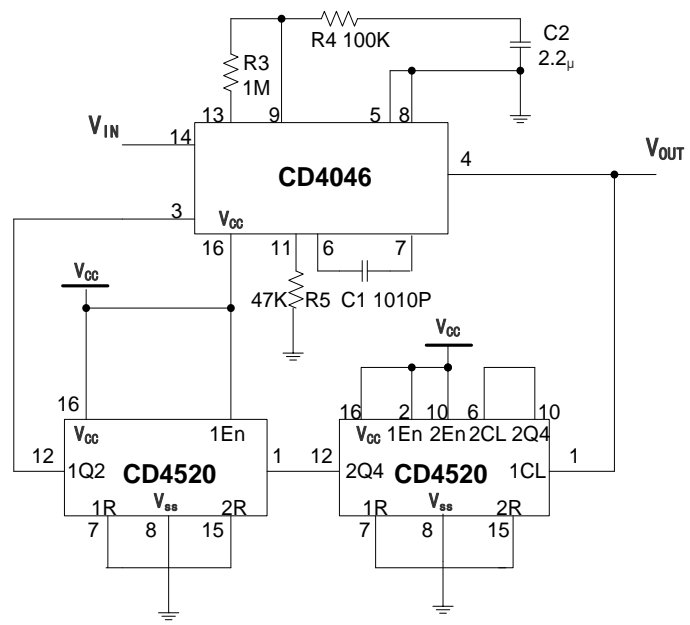

Figure 6. Frequency multiplier circuit

\section{Design of the driving circuit of IPM[12]}

DSP output 6 channel PWM control pulse which through high speed optical isolation buffer and then output to the control end of drive circuit, as the control signal of the IGBT module.Between PWM wave output end of the DSP controller and control signal input end of the IGBT where is connected with a high speed optocoupler which plays the role of isolation interference, driver amplifier and separating the high voltage inverter circuit and low voltage control circuit[13]. The design philosophy for isolation and driving circuit of IPM module shown in Fig .7. The highspeed photoelectric coupling isolation chip HCPL-4504 had be used.

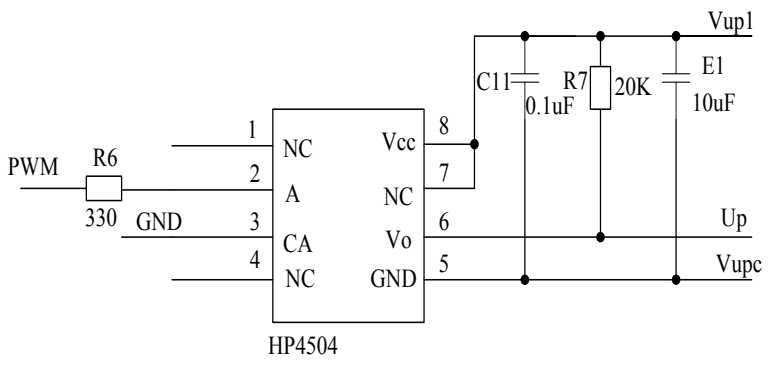

Figure 7. Drive circuit

\section{SOFTWARE REALIZATION}

Fig .8 shows the module structure of software systems. The system lower position machine software uses DSP programming software CC2000,which has powerful functions and it is the key to achieving high accuracy and high speed algorithm.Computer system software uses the visualization software Delphi as the tool and it was developed in Windows environment[14-15].

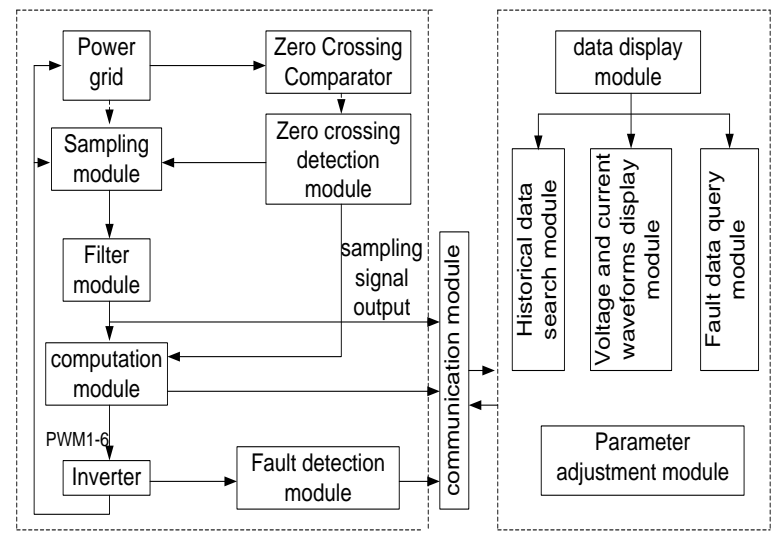

Figure 8. The systemfunction modules of the softwarestructure diagram

\section{EXPERIMENTAL RESULT}

After the completion of the development of STATCOM $\pm 50 \mathrm{kVA}$ experimental prototype based on the IGBT module, we conducted on load commissioning. Giving load resistance cabinet of $10 \mathrm{~kW}$ to access $380 \mathrm{~V}$ power grid to simulate the impact of reactive load and record the changes of STATCOM access point voltage before and after the impact.Fig .9 shows the public connection point voltage Upcc experimental waveform in the process of STATCOM before and after operation by a sudden increase of reactive load.

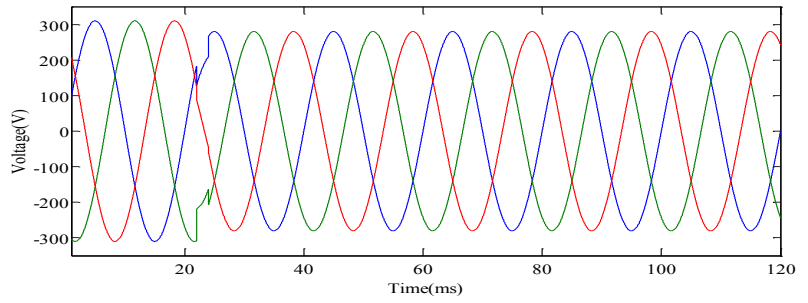

(a)Upcc voltage waveform before the operation of STATCOM

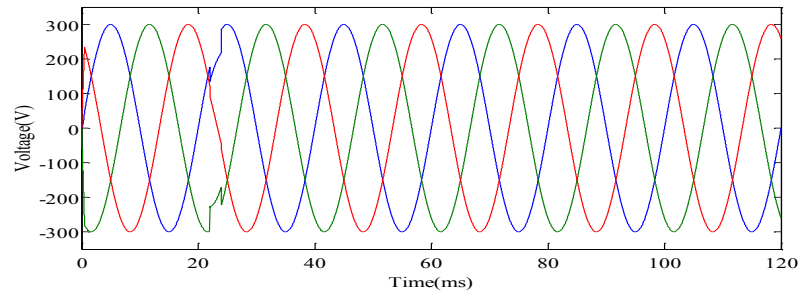

(b)Upcc voltage waveform after the operation of STATCOM

Figure 9. Experimental waveform of voltage control

Fig .9(a) shows that a sudden increase of reactive load causing a decrease in the public connection point voltage and the peak value is less than $310 \mathrm{~V}$.After STATCOM putting into operation, from Fig .9(b) can be seen, because of the compensation effect of STATCOM, the public connection point voltage peak soon returned to the $310 \mathrm{~V}$. 
Its response time is slightly bigger than one cycle.This proves that the effect of voltage control is effective and feasible.

\section{CONCLUSION}

This paper introduced the working principle and the structure system of static synchronous compensator. For the purpose of reactive power compensation of distribution network, aiming at the problem of distribution network electric energy qualityputting,the paper put forward the hardware and software design method of static synchronouscompensator based on DSP. Completed the device experiment of closed-loop at voltage compensation and gived the corresponding experimental results. At last it analyzed experimental resultsare in detail.The experimental results show that, the STATCOM devices based on the design method which have an excellent effect of reactive power compensation, which can maintain the public connection point voltage stability in the vicinity of a given value, which has a good application prospect in Engineering.

\section{REFERENCES}

[1] Sun Zhong-quan.Research and application of power saving technology[J].Power System Protection and Control,2009,37(24):227-229.

[2] Tu Chun-min,Li Hui,Tang Jie,Luo An.Analysis and suppression of the effect of asymmetric grid voltage of D-STATCOM [J].Journal of Electrician Technique,2009(10).

[3] Yang You-liang.Principle of Automatic Control [M].Electronic Industry Press,2011.
[4] Zhu Yong-qiang,Liu Hua,Song Qiang and so on.Optimization design of DSTATCOM unbalanced load compensation current [J]. Automation of electric power systems,2005,29(8):65-70.

[5] Guo Xiao-jiang,Tang Yong,Guo Qiang,et al.Influence factors and theory for CIGRE MISCR index[J].Power System Protection and Control,2012,40(9):69-74(in Chinese).

[6] Su Kui-feng,Lv Qiang,Geng Qing-feng and so on.The principle and development of TMS320F2812 [M]. Beijing:Publishing House of electronics industry,2005.

[7] Lei Xian-zhang,Retzmann D,Weinhold M.Improving power quality of the distribution network by using electric power quality regulator[J]. Power system technology,2000,24 (8):8-12.

[8] Chen Xiu-yu,A.M.Gole,Han Minxiao,et al.Influence of the MIIF index on operation of multi-infeed HVDC systems[C]//Electrical Power and Energy Conference.Winnipeg:IEEE,2011:216-221.

[9] Chunyi Guo,Chengyong Zhao.Supply of an entirely passive AC network through a double-infeed HVDC system[J].IEEE Transactions on Power Electronics, 2010,25(11):2835-2841.

[10] Han An-tai,Liu Zhi-fei,Huang Hai and so on.The controller principle and the application in motion control system of DSP[M] Beijing:Tsinghua University press,2003.

[11] Liu Hua-dong,Zhang Ding-hua,Tang Jian-yu,et al.Research on direct voltage control of STATCOM for mitigating electric arc furnaces flicker[J].Transactions of China Electrotechnical Society,2012,27(9):41-47

[12] Dang Jian-fei,Dang Yan-li,Song Fu-gen.Study on the influence of the three-phase unbalanced operation and methods of reactive power compensation[J].Electrical Engineering,2012(8):51-54.

[13] Wang Zhao-an,Yang Jun,Liu Jin-jun.Harmonicelimination and reactive power compensation [M].Beijing:Machinery industry press, 1998 .

[14] Liu Peng,Lin Hui.Design of missile rudder electric loading system controller [J].Computer measurement and control,2010,18(8):18251827.

[15] Tang Ci.Nonlinear control method of DSTATCOM[J].Electric Power Automation Equipment,2011,31(3):18-22. 